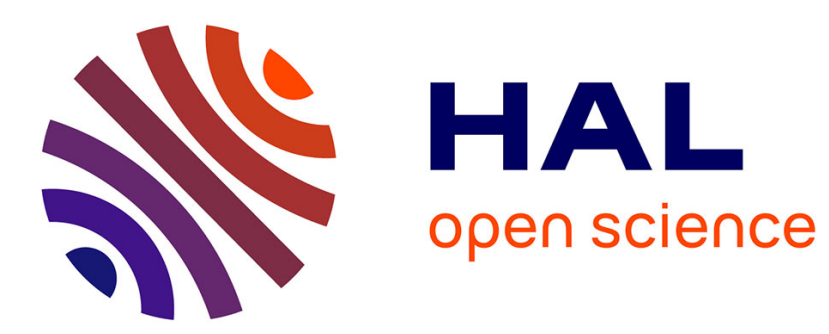

\title{
Near-field BLEVE overpressure effects: The shock start model
}

\author{
A.M. Birk, F. Heymes, R. Eyssette, Pierre Lauret, L. Aprin, Pierre Slangen
}

\section{To cite this version:}

A.M. Birk, F. Heymes, R. Eyssette, Pierre Lauret, L. Aprin, et al.. Near-field BLEVE overpressure effects: The shock start model. Process Safety and Environmental Protection, 2018, 116, pp.727-736. 10.1016/j.psep.2018.04.003 . hal-02011899

\section{HAL Id: hal-02011899 \\ https://hal.science/hal-02011899}

Submitted on 21 Nov 2019

HAL is a multi-disciplinary open access archive for the deposit and dissemination of scientific research documents, whether they are published or not. The documents may come from teaching and research institutions in France or abroad, or from public or private research centers.
L'archive ouverte pluridisciplinaire HAL, est destinée au dépôt et à la diffusion de documents scientifiques de niveau recherche, publiés ou non, émanant des établissements d'enseignement et de recherche français ou étrangers, des laboratoires publics ou privés. 


\title{
Near-field BLEVE overpressure effects: The shock start model
}

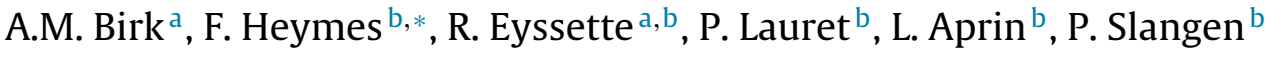 \\ a Department of Mechanical and Materials Engineering, Queen's University, Kingston, K7L 3N6, Ontario, Canada \\ ${ }^{\mathrm{b}}$ LGEI, IMT Mines Ales, Univ Montpellier, Ales, France
}

Keywords:

BLEVE

Explosion

Blast overpressure

Shock initiation

Risk assessment

\begin{abstract}
A B S T R A C T
This paper presents the results of a small scale experimental study of BLEVE overpressure effects. Testing consisted of a sealed aluminum tube $(0.6 \mathrm{~L})$ filled with either water or propane, being heated by a flame until the internal pressure led to catastrophic failure and explosion. Three parameters were controlled during the experiments: the failing pressure, the weakened length on the tube and the fill level. BLEVEs were obtained with tests involving water and propane. Blast gages and optical techniques were used to characterize the shock wave escaping from the failing tube. The results obtained suggest that the lead shock was primarily generated by the vapor space. Overpressure results obtained were compared with the predictions of existing models and found to be in reasonable agreement except for overpressures measured vertically above the cylinder where the overpressures were highest. A prediction model based on only vapor space characteristics was developed. Images show that the shock was fully formed at some distance away from the vessel opening and this was due to the non-ideal opening of the vessel. The model developed was based on the characteristics of the shock when fully formed away from the tube. These characteristics were defined using a combination of imaging, pressure measurements, and predictions from shock tube theory.
\end{abstract}

\section{Introduction}

A Boiling Liquid Expanding Vapor Explosion, or BLEVE, is a major hazard in the industrial landscape where storage tanks of Pressure Liquefied Gas are common. Pressure vessels are subject to various types of aggressive conditions that can weaken them and can sometimes lead to failure, e.g. corrosion, the impact of a projectile, or exposure to fire (Heymes et al., 2013).The case of fire engulfment of a vessel is investigated in this study because it is the most prevalent source of BLEVEs according to the literature (Abbasi and Abbasi, 2007; Hemmatian, 2016). In such a case the liquefied gas in the vessel is heated, increasing the pressure significantly. Pressures higher than the normal functioning pressure may be the result and the wall of the vessel is severely weakened at the top by the temperature increase due to the poor cooling properties of the vapor. An important characteristic of BLEVE accidents is that the fluid in the vessel is usually at a temperature much higher than its atmospheric boiling temperature. The combination of high pressure and weak structure leads to a crack that propagates along the length of the vessel allowing the pressurized fluid to be released. The vapor

\footnotetext{
* Corresponding author.

E-mail address: frederic.heymes@mines-ales.fr (F. Heymes).
}

first expands violently, leading to a fast drop in pressure within the vessel where the liquid is in a superheated state and boils explosively. In some scenarios, the vessel opens fully, releasing all of its contents and leading to a BLEVE.

The consequences of such an event are blast overpressure, projection of vessel fragments, as well as possible fire and/or toxic hazards depending on the stored gas properties. A fireball, though, is not a necessary consequence of a BLEVE. It should be noted that a BLEVE is the mechanical explosion due to liquefied gas release. This study is focused on the overpressure consequences of such a phenomenon.

Overpressure prediction is a major factor in predicting BLEVE impact. The impact on the surroundings of a BLEVE generated blast needs to be understood in order to better prevent chain reaction effects and casualties. Various parameters are required to describe the full effects of overpressure: the peak overpressure of the blast, the positive overpressure impulse and its duration, the drag loading due to the dynamic pressure exerted on a structure. The wide range of prediction models currently available in the literature focus on the maximum first peak overpressure. These models also focus on the far field effects.

Various overpressure prediction models with different approaches to the BLEVE phenomenon are available. The TNTequivalent method (Baker et al., 1977; Van den Berg and Lannoy, 
1993) is widely used for far-field overpressure prediction. It involves the calculation of the energy contained in the vessel and released in the blast. Several models are available that consider either the isentropic expansion energy (Prugh, 1991), or irreversible expansion energy (Planas-Cuchi et al., 2004), or the excess superheat energy (Casal and Salla, 2006; Genova et al., 2008). This TNT-approach is easy to implement and well validated for far-field overpressure prediction.

However, the complex opening mechanism and phase change contributions cause the TNT-equivalent model to be an overpredicting approach to near-field BLEVE blasts. Van den Berg (van den Berg et al., 2004) proposed a model based on Computational Fluid Dynamics (CFD) by calculating the evaporation rate of a vessel full of liquid. This model predicts the overpressure caused by the sudden expansion of the vessel contents. It is in better agreement with the constraints of the physical evaporation phenomenon, especially close to the vessel. Some conservative hypotheses (no vapor in the vessel, instantaneous vessel disintegration and evaporation) do not solve a few key problems of the near-field BLEVE overpressure calculations such as the contribution of the vapor expansion and the liquid boiling. Van den Berg assumes that the flash evaporation is instantaneous and that the shock is produced by the expansion of this vapor. A more recent approach (Yakush, 2016) provides a reasonable physical description of the BLEVE phenomenon with CFD modelling of the expansion wave propagation in the liquid, assuming instant equilibrium boiling when the thermodynamic conditions are reached. This model shows that the vapor generates a shock while the velocity of the boiling wave through the liquid restricts shock formation due to liquid expansion. Finally, the prediction model of Laboureur (Laboureur et al., 2015) introduced the non-ideal opening of a vessel into the prediction. This model estimated the starting shock position and overpressure and extrapolated it through distance with hemispherical decay. The starting position of the shock was assumed to be some factor times the vessel diameter which determines the overall scale of the release. The predictions were empirical, experiment based, and validated with simulations (van den Berg et al., 2004).

The issue raised by these prediction models is the definition of the contribution of each phase. Most of the energy based models consider expansion energy from the vapor space added to expansion energy from the vapor generated by the flashing fraction of liquid in order to calculate the maximum overpressure. However, some authors (Baker, 1985; Birk et al., 2007) state that only the vapor contributes to the maximum first peak overpressure. Moreover, additional phenomena such as directionality need to be taken into account in the overpressure prediction models. Empirical factors adding the effect of this phenomenon are used, based on pressure vessel bursts experiments (CCPS - American Institute of Chemical Engineers, 1994). But none have been validated for BLEVE so far.

This paper first presents results of tests involving a small scale experimental apparatus with overpressure data and high speed imaging. These results are compared to existing prediction models for validation. Finally, a physical approach to the shock start phenomenon is presented with a modelling method that does not require evaluation of the expansion energy.

\section{Material and methods}

Experiments involving small scale BLEVEs were undertaken (Birk et al., 2016). The apparatus used consisted of 6061T6 aluminum tubes, $5 \mathrm{~cm}$ in diameter, $30 \mathrm{~cm}$ long, with a wall thickness of $1.65 \mathrm{~mm}$ and an inner volume of $0.6 \mathrm{~L}$. The tubes were annealed and some aluminum was removed through machining, to produce a specific weakened length and reduced burst pressure (Fig. 1).This weakened length is referred to as a slot. The ends of the tubes were sealed with Swagelok fittings. The BLEVE case studied here was failure through exposure to fire. During testing, the tube was filled remotely with water or commercial propane (roughly $80 \%$ propane, $20 \%$ other hydrocarbons), up to a known quantity. It was then pressurized to failure through a slow heating process using a small burner placed below the tube (Fig. 2 ). The controlled variables of these tests were the burst pressure, and the weakened length on the tube.

Failure conditions were monitored with pressure sensors located on the filling and venting pipes, and two type $\mathrm{K}$ thermocouples mounted inside the tube (one in liquid and one in vapor). The monitoring sensors are sampled at $10 \mathrm{~Hz}$. Blast gages (PCB 137A23 piezoelectric with a sample rate of $200 \mathrm{kHz}$ ) were set at various heights and angles to the slot in the tube. Three pencil type blast gages were mounted on a vertical axis above the experimental tube at distances of $0.3 \mathrm{~m}, 0.4 \mathrm{~m}$ and $0.9 \mathrm{~min}$ order to observe the decay above the tube. Except in the case of the small scale results (Laboureur, 2012), previous mid-scale and large scale BLEVE experiments did not measure the overpressure above the vessel, but measured it only from the sides.

Other gages were located at $45^{\circ}$ (down from tube top on side) and horizontal (tube side) to the tube to observe the directional influence of the opening process on the overpressure at distances varying from $0.25 \mathrm{~m}$ to $0.4 \mathrm{~m}$.

High speed imaging was used to capture the rupture mechanism and for retroreflective shadowgraphy of the shock propagation (Hargather and Settles, 2009).Observation of the phenomenon inside the tube was done through a $38 \mathrm{~mm}$ quartz window constructed at one end of the tube. The imaging was carried out using two Phantom V711 high speed video cameras. The lenses used were a Nikon $105 \mathrm{~mm}$ (f/8) for PILS and a Tamron $300 \mathrm{~mm}(\mathrm{f} / 5.6)$ for the end window imaging.

Load cells were mounted under the experimental tube to measure the load on the ground generated by the BLEVE.

\section{Experimental results}

\subsection{Summary of experiments}

Twenty tests were performed with tubes filled with an average mass of $300 \mathrm{~g}$ of water resulting in eleven BLEVEs and nine partial failures. Over all the tests performed with water, the failure pressure ranges from 9 to $50 \mathrm{bar}$, thus the liquid volume fraction ranges from 62 to $70 \%$, assuming equilibrium before rupture. Twelve tests were performed on tubes filled with propane resulting in ten BLEVEs. Over all the tests performed with propane, the mass of propane used per test ranges from $140 \mathrm{~g}$ to $156 \mathrm{~g}$, the failure pressure ranges from 8 to 40 bar, thus the volume fraction of liquid ranges from 50 to $66 \%$. The failure conditions, evaluated from the pressure sensor and thermocouple in the liquid phase for all of the cases, are summarized in the P-T diagrams shown in Fig. 3. The failure conditions for most of the tests were near equilibrium at saturation conditions. A slight offset with respect to the saturation curve is visible. It is due to fast heating and the presence of temperature stratification in the tube leading to a faster pressurization of the vapor space but a weaker explosive boiling.

\subsection{Pressure peaks data}

Measurements from all of the blast gages are summarized in Table 1 , where $\mathrm{R}$ is the distance from the top of the tube to the sensor of the blast gage.

The influence of the direction of measurement on the maximum overpressure is clearly shown by these results. The ratio between 


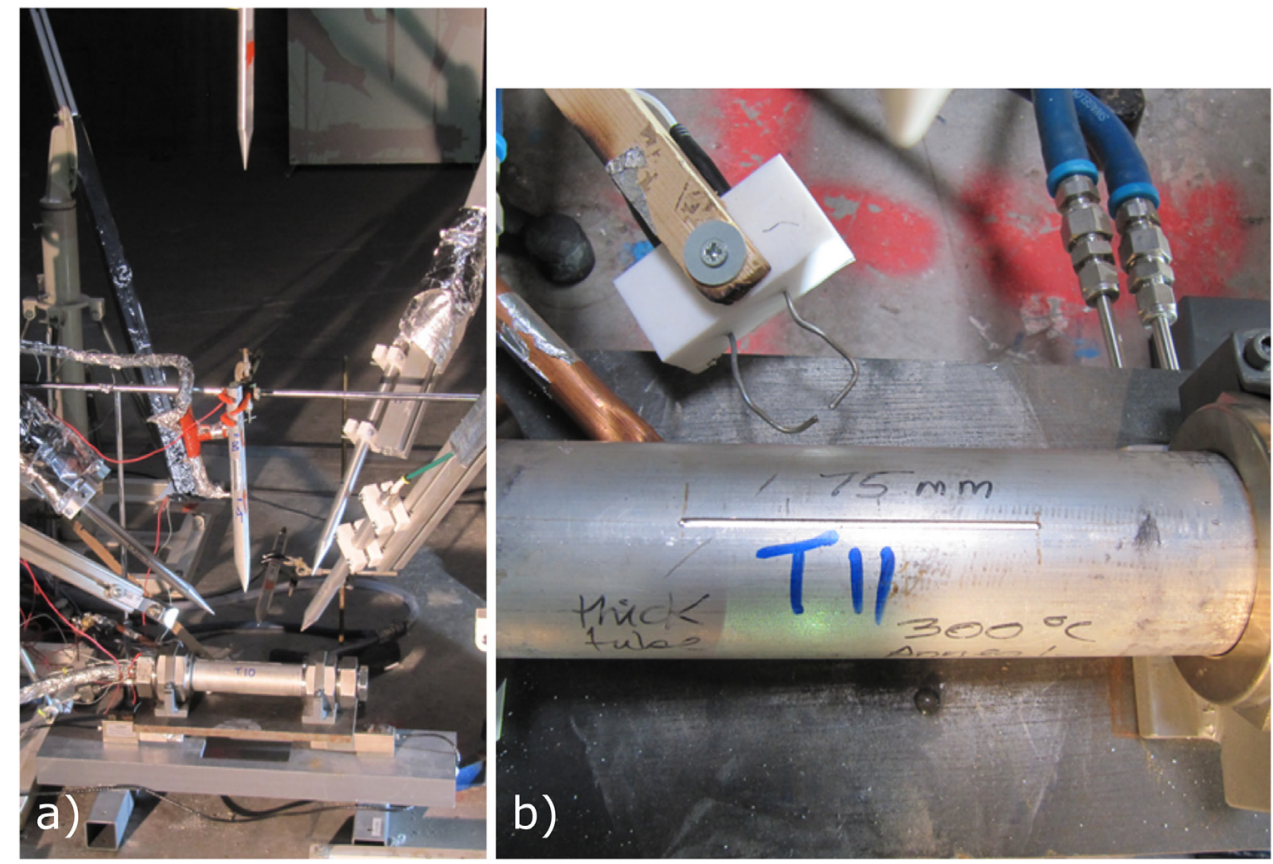

Fig. 1. Small scale BLEVE apparatus (a) global view, (b) machined slot on the tube for controlled failure.

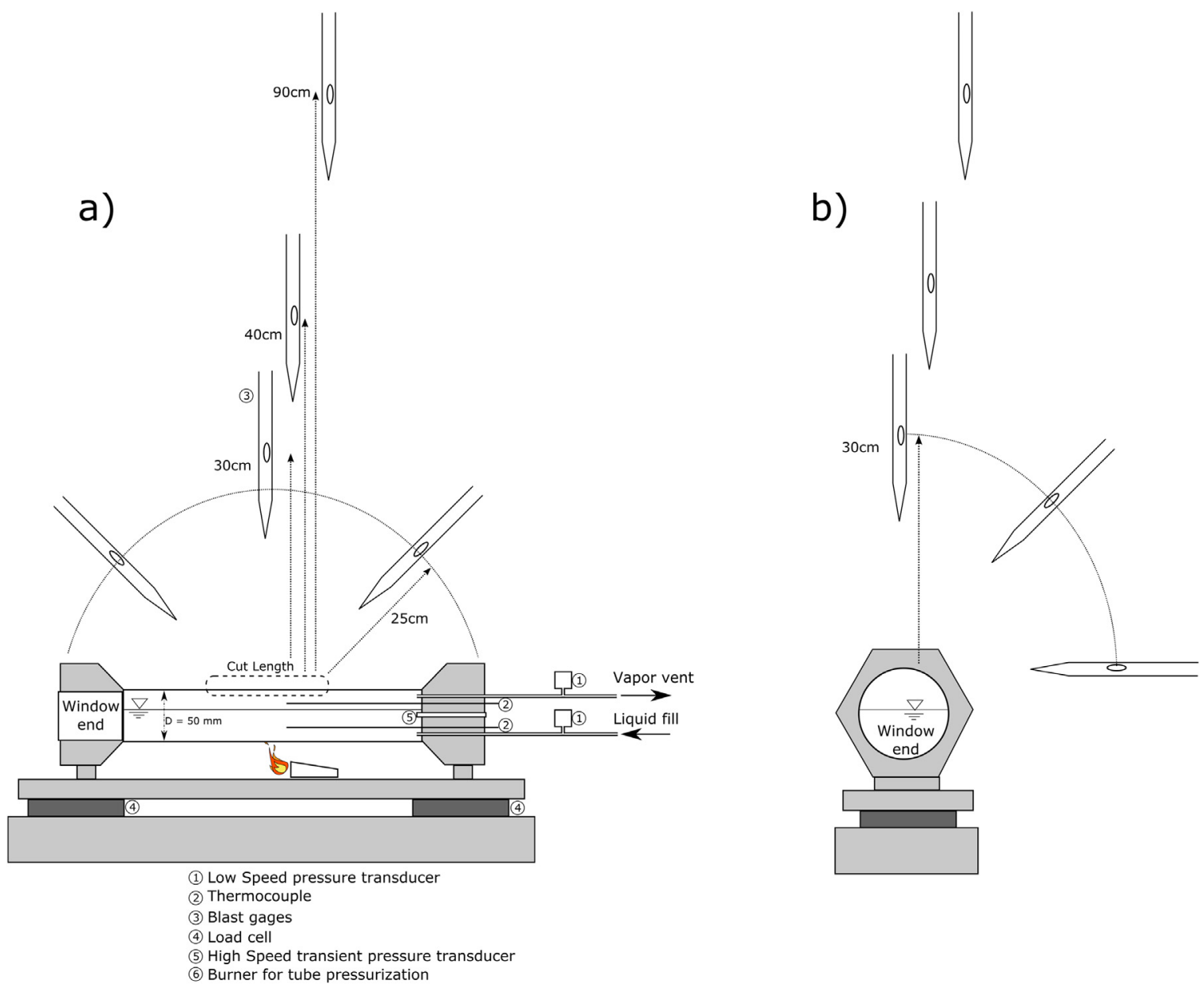

Fig. 2. Experimental tube (a) front view, (b) end view. 

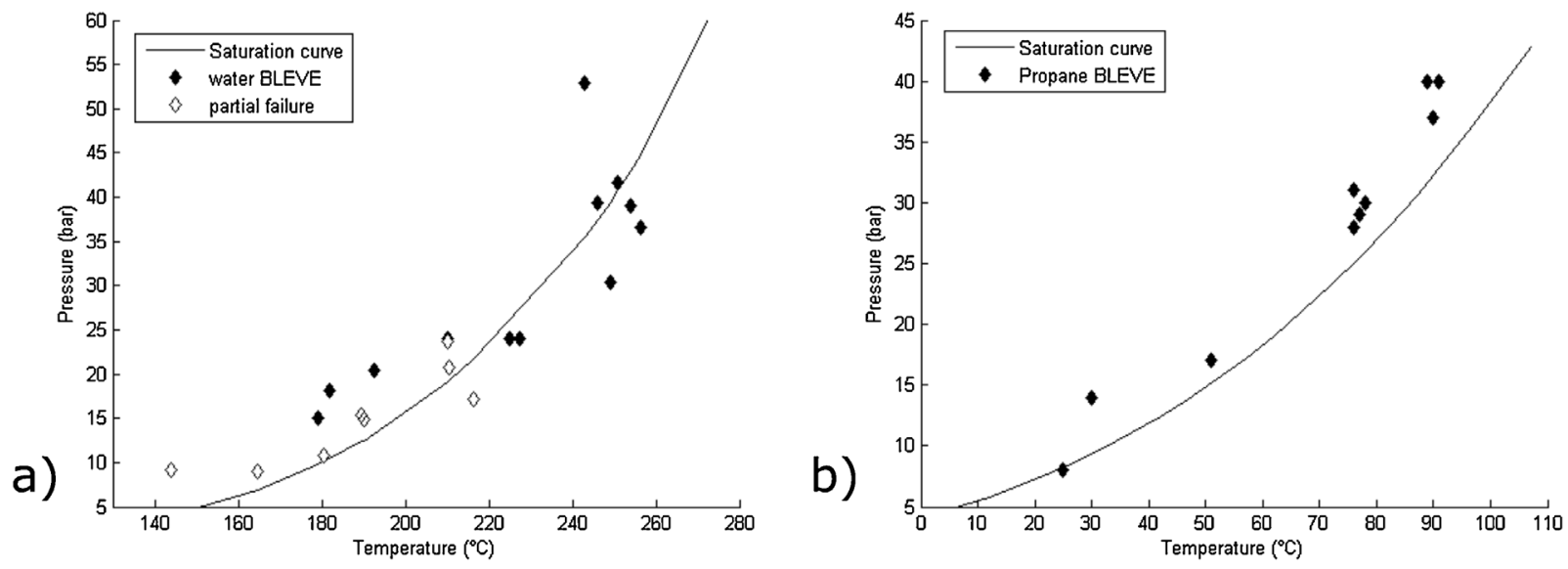

Fig. 3. Summary of test results (a) Water tests, (b) Propane tests.

Table 1

Experimental data from small scale BLEVE with propane: measurements from blast gages above and to the sides of the vessel.

\begin{tabular}{|c|c|c|c|c|c|c|c|c|c|c|}
\hline \multirow[t]{2}{*}{ \# } & \multicolumn{4}{|c|}{ Failure conditions } & \multicolumn{2}{|c|}{ Vertical overpressure } & \multicolumn{2}{|l|}{$45^{\circ}$ overpressure } & \multicolumn{2}{|c|}{$\begin{array}{l}\text { Horizontal } \\
\text { overpressure }\end{array}$} \\
\hline & Mass (g) & $\% \operatorname{liq}^{a}$ & $\mathrm{P}_{\text {fail }}(\mathrm{bar})$ & $\mathrm{T}_{\text {fail }}(\mathrm{K})$ & $\mathrm{R}(\mathrm{m})$ & $\Delta \mathrm{P}(\mathrm{kPa})$ & $\mathrm{R}(\mathrm{m})$ & $\Delta \mathrm{P}(\mathrm{kPa})$ & $\mathrm{R}(\mathrm{m})$ & $\Delta \mathrm{P}(\mathrm{kPa})$ \\
\hline 1 & 150 & $66 \%$ & 40 & 367 & $0.29 / 0.39$ & $65.4 / 53.6$ & 0.41 & 29.25 & 0.29 & 40.7 \\
\hline 2 & 150 & $66 \%$ & 40 & 375 & $0.26 / 0.36$ & $88 / 59.1$ & 0.39 & 29.87 & 0.29 & 41.16 \\
\hline 3 & 140 & $51 \%$ & 30 & 351 & $0.28 / 0.38$ & $71.8 / 38.8$ & 0.34 & 29.99 & 0.29 & 30.53 \\
\hline 4 & 150 & $56 \%$ & 28 & 347 & $0.28 / 0.38 / 0.92$ & $48.76 / 25.90 / 7.58$ & $0.28 / 0.30 / 0.31$ & $18.59 / 29.05 / 26.39$ & 0.29 & 20.25 \\
\hline 5 & 156 & $50 \%$ & 8 & 297 & $0.28 / 0.38 / 0.92$ & $28.30 / 11.60 / 3.84$ & $0.25 / 0.26 / 0.31$ & $3.27 / 9.12 / 6.08$ & 0.295 & 2.21 \\
\hline 6 & 150 & $61 \%$ & 37 & 374 & $0.28 / 0.38 / 0.92$ & $60.00 / 49.00 / 16.95$ & $0.25 / 0.26 / 0.32$ & $42.26 / 37.43 / 39.25$ & 0.3 & 40.36 \\
\hline 7 & 155 & $60 \%$ & 31 & 349 & $0.28 / 0.38 / 0.92$ & $76.80 / 47.50 / 13.79$ & $0.25 / 0.26 / 0.32$ & $33.11 / 26.36 / 31.36$ & 0.295 & 26.07 \\
\hline 8 & 153 & $58 \%$ & 29 & 357 & $0.28 / 0.38$ & $44.2 / 34.5$ & $0.26 / 0.32$ & $23.79 / 27.55$ & 0.29 & 23.53 \\
\hline 9 & 152 & $53 \%$ & 17 & 350 & $0.28 / 0.38$ & $24.5 / 17.9$ & $0.26 / 0.32$ & $17.83 / 15.92$ & 0.29 & 7.06 \\
\hline 10 & 154 & $52 \%$ & 14 & 324 & $0.28 / 0.38$ & $20.13 / 13.13$ & $0.26 / 0.32$ & $12.47 / 11.48$ & 0.29 & 3.81 \\
\hline
\end{tabular}

a Volume fraction of liquid at failure conditions (in \%).

side overpressures and top overpressures is calculated between gages placed at similar distances $(0.3 \mathrm{~m})$ for each case and averaged over all successful BLEVE experiments. Between the $45^{\circ}$ direction of measurement and the vertical, the ratio is 0.45 . Between the horizontal and vertical measurements, the ratio is 0.35 . There is a clear dependence on the opening dynamics of the vessel on how the maximum first peak overpressure is distributed around the tube.

An example of pressure measurement is given in Fig. $4^{*}$ a. A characteristic strong first overpressure is observed, followed by a negative phase and a second peak. These are known to be characteristic pressure peaks for a vapor explosion(Baker, 1985). A third increase in pressure then follows. A study by Birk(Birk et al., 2007) presents similar results from a larger scale BLEVE. The origin of the third peak is yet unknown but it is hypothesized that the liquid boiling contributes to this overpressure. The pressure signal observed in the results of the present work satisfies this hypothesis. However, the oscillating behavior following the third rise may suggest a potential measurement aberration.

\subsection{Phase change dynamics}

When the tube opens, the first thing visible to bare eye is a white cloud escaping through the opening (Fig. 5). Due to the white aspect of this cloud, it is assumed to be a 2-phase mixture, representing the vapor space expanding from the high-pressure tube and condensing when exposed to ambient pressure, thus a condensation cloud is observed.

Then, coupling the imaging from both sides of the tube (the radial direction of the shadowgraph, see Fig. 6, and the axial window visualization, see Fig. 7), the following sequence of events is used to investigate the hypothesis that vapor is the sole contributor to the first shock. A shock is formed ahead of the condensation cloud observed before (see arrow in Fig. 6b). While the tube opens more (Fig. 6 and Fig. 7c), the condensation cloud grows, and the shock propagates. It is important to note that the shock is always ahead of the cloud observed. At $0.88 \mathrm{~ms}$ after the opening of the vessel, the interface between the liquid and the vapor starts thickening showing the point at which the boiling wave reaches the window end of the tube (see Fig. 7d). This suggests that the boiling occurs after the vapor space expanded out of the tube, allowing the pressure to drop in the tube and the liquid to enter the superheated state. It can be seen that the shock occurs ahead of the condensation cloud, which occurs ahead of the boiling wave. Thus, the boiling liquid cannot contribute to the first shock.

\section{Overpressure prediction models}

In this section, available overpressure prediction models are compared with the present new blast data. The shock start model is then presented and discussed.

\subsection{Models based on global expansion energy}

Experimental results are compared to prediction models that calculate the expansion energy converted into overpressure, to then deduce the overpressure from literature data such as the TNTcurve (Baker et al., 1977).

The models of Prugh (Prugh, 1991) and Planas-Cuchi (PlanasCuchi et al., 2004) are based on the calculation of the expansion energy assuming respectively an isentropic and an irreversible adiabatic process. Another model by Casal (Casal and Salla, 2006) presents a model based on estimation of superheat energy, defined 

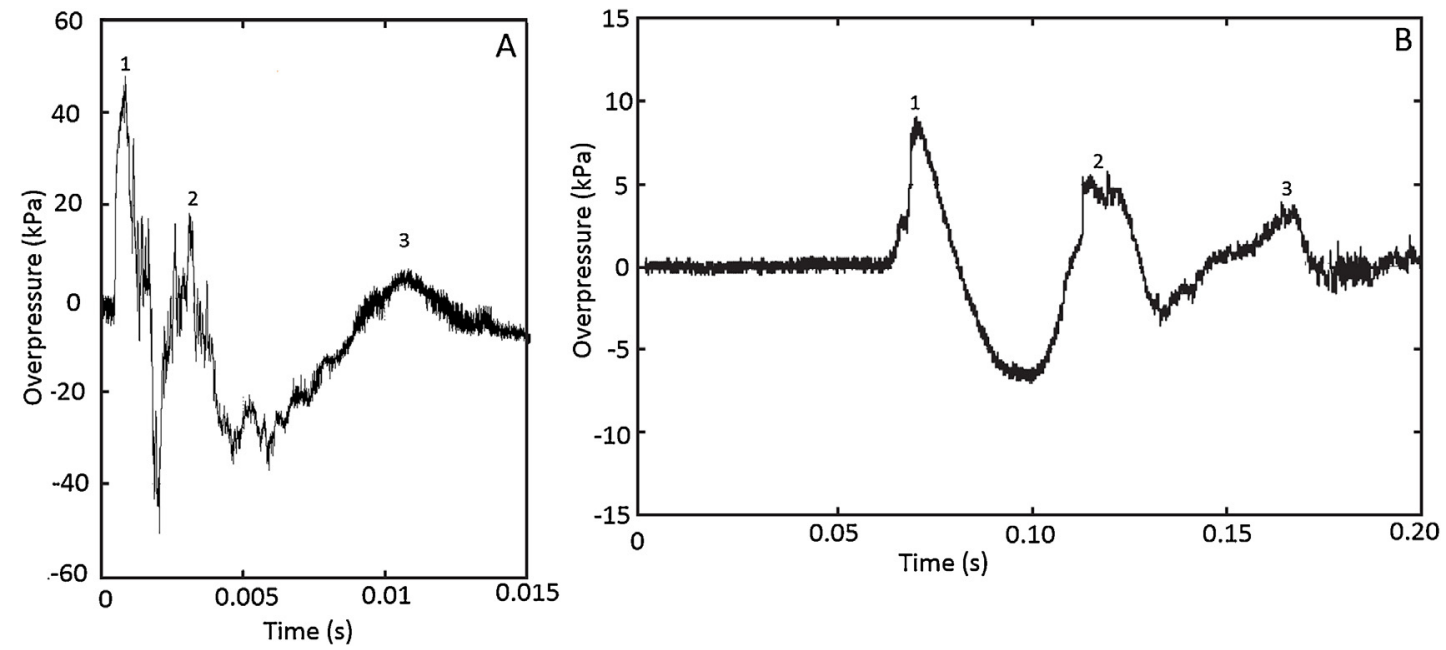

Fig. 4. Overpressure measurement: a) Case 4, top $R=0.28 \mathrm{~m}$; b) Birk 2007, side $\mathrm{R}=10 \mathrm{~m}$ (Laboureur et al., 2015).

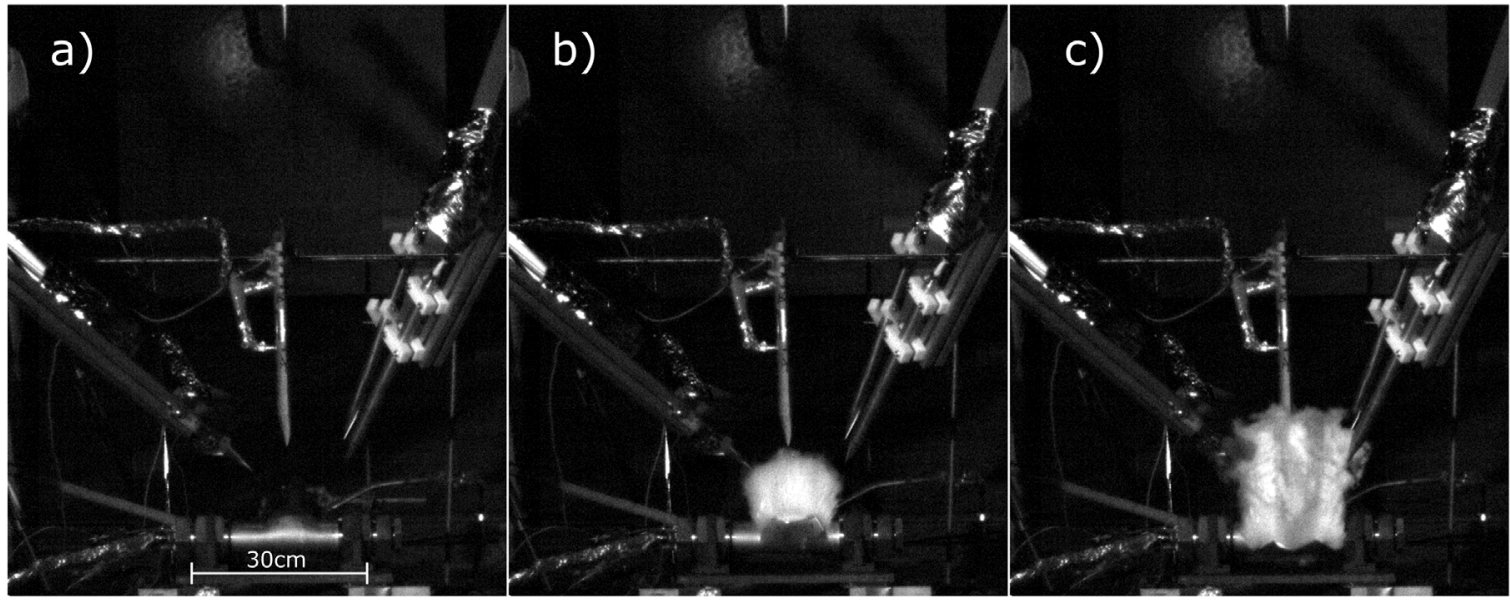

Fig. 5. Direct High Speed imaging of the tube opening ( $4000 \mathrm{fps}$ ) (case 4, a) $0.25 \mathrm{~ms}$ b) $0.5 \mathrm{~ms} \mathrm{c}$ ) $0.75 \mathrm{~ms}$ after start of the opening).
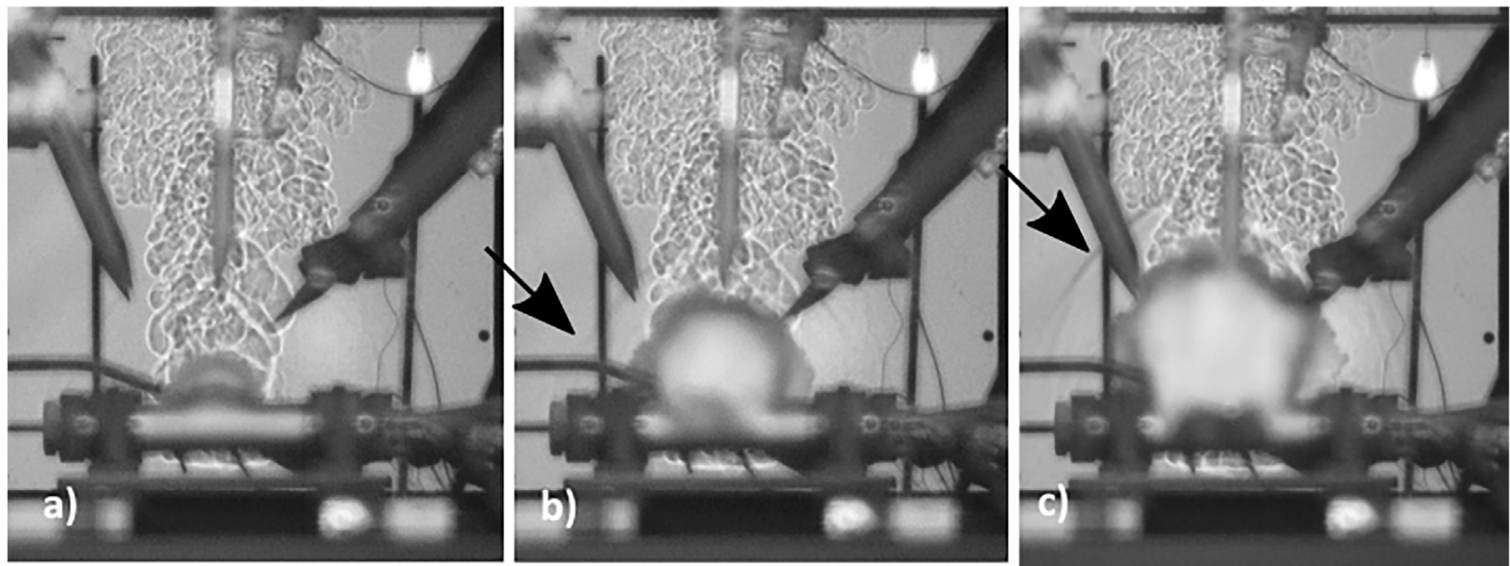

Fig. 6. Retroreflective shadowgraph of the early stage of a BLEVE ( $20000 \mathrm{fps}$ ) (case 4 , a) $0.2 \mathrm{~ms}$ b) $0.45 \mathrm{~ms}$, c) $0.55 \mathrm{~ms}$ after start of the opening).

as the difference of enthalpy of the liquid before rupture, and its enthalpy at saturation temperature corresponding to atmospheric pressure, after expansion. Lastly, Birk (Birk et al., 2007) presents a model based on the sole evaluation of vapor expansion, calculating the difference of internal energy before and after failure in the vapor space of the vessel. Details on the previously exposed mod- els and reference curves are summarized by Laboureur (Laboureur et al., 2014).

Experimental data points are compared to the TNT-curve as follow: for each case and probe, the scaled distance is calculated from a chosen model. Then the couple (scaled distance; measured overpressure) is placed on the TNT-curve plot. By comparing the 

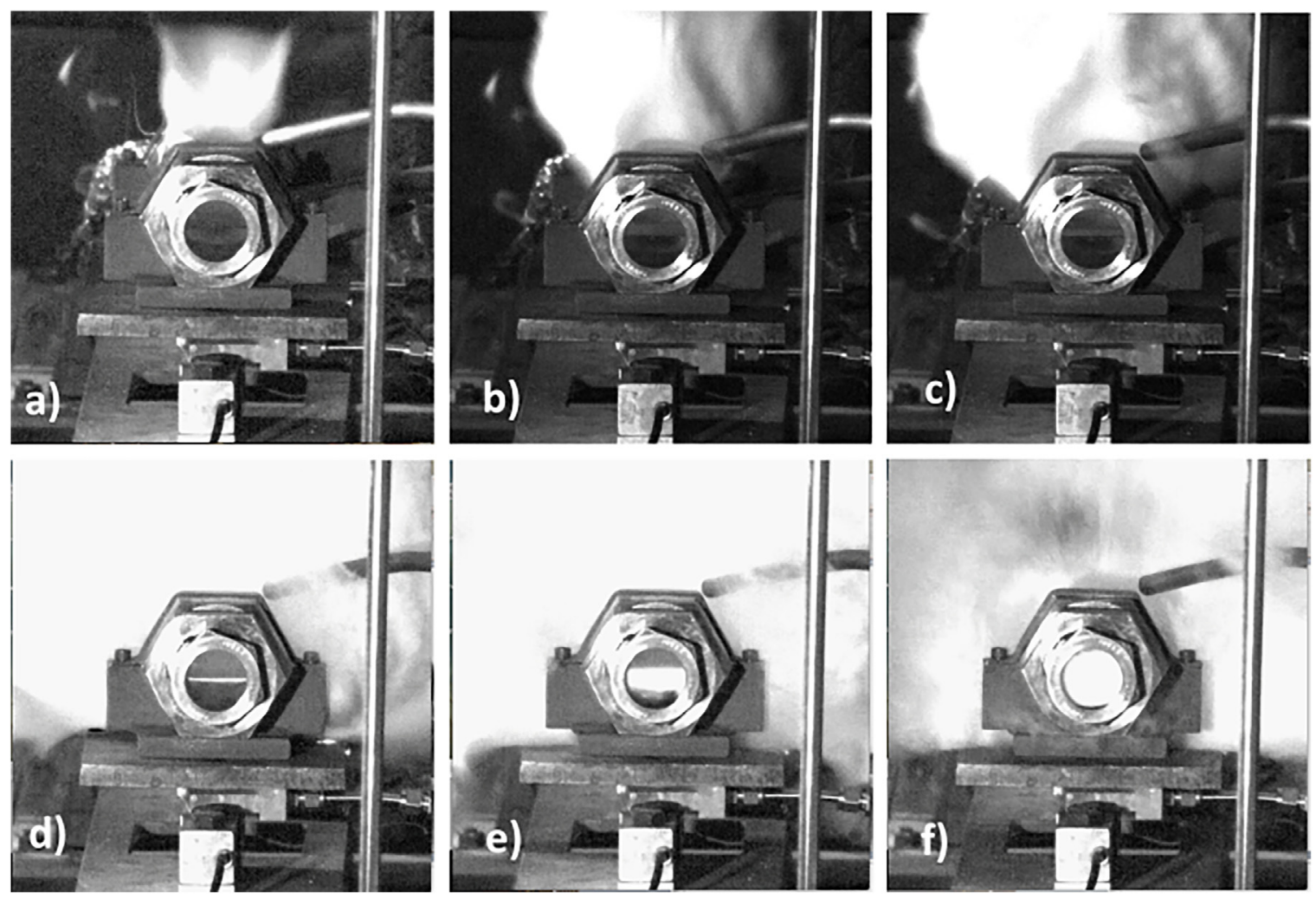

Fig. 7. View of end window at early stage of a BLEVE (case 4,a) $0.2 \mathrm{~ms}$, b) $0.44 \mathrm{~ms}, \mathrm{c}$ ) $0.56 \mathrm{~ms}$, d) $0.88 \mathrm{~ms}$, e) $1.12 \mathrm{~ms}$, f) $2 \mathrm{~ms}$ after start of the opening) (Birk et al., 2016 ).

position of the points with regards to the TNT-curve, one can gage if the chosen prediction model estimate well the prediction energy involved in the explosion, based on the assumption that TNT has a similar behavior than a BLEVE in converting energy to overpressure.

Prugh and Planas-Cuchi models present similar tendencies of predictions, particularly noticeable for the sensors located furthest from the tube (series of points on the far right both graphs Fig. 8). These tendencies do not follow the decay described by the TNTcurve. This can imply 2 things: the TNT-curve do not describe well the small scale BLEVE behavior in the far-field, or these two do not consider part of the physics involved in modelling the energy of expansion. It is worth noticing that predictions through Prugh's predictions are more conservative than Planas-Cuchi's, validating the hypothesis of each model. It underestimates some overpressure measurements in the near-field, which is a problem if used as a prediction tool for safety. Planas-Cuchi's predictions are more accurate when compared to TNT prediction. The predictions of experimental blast with Casal models do not show the trend noticed earlier (Fig. 9). Once again, the isentropic approach is more conservative than the irreversible one. Moreover the predictions made with the irreversible approach, less conservative of all, are more concentrated around the TNT-curve than the ones from Planas-Cuchi's approach (Fig. 10). This implies that Casal irreversible model seem to express the physics closest to a TNT explosion behavior, with BLEVE parameters. Finally, the vapor expansion model from Birk (Fig. 11) seems to show the best tendency between experimental prediction and the TNT prediction.

From experimental results, overpressure varies depending on the direction of propagation from the vessel. It is stronger above the vessel, gets weaker at $45^{\circ}$ angle, and weaker on the horizontal plane radially to the cylinder. However none of the models were designed to predict overpressure from the top, as only side experimental measurements were available for validation. This statement justifies the underestimations made by less conservative models
(Planas-Cuchi Fig. 8b, Casal irreversible Fig. 9b). It also shows that direction needs to be considered for further modelling.

\subsection{Expansion-controlled model (van den Berg et al., 2004)}

Another model mentioned in the literature is the expansioncontrolled model of Van den Berg (van den Berg et al., 2004), from which charts for various substances, particularly propane, were developed (Van den Berg, 2008). In this model, the experimental data are scaled based solely on the initial mass of propane (liquid and vapor) in the tube. The scaling parameter $m^{\frac{1}{3}}$ varies much less between all the experimental tests compared to the scaling parameters chosen with previous models. Predictions from Van den Berg applied to experimental are conservative for all tests. Experimental results follow a decay similar to the results from Van den Berg simulation, over a full order of magnitude along the x-axis (Fig. 11).

\subsection{New predictive model: the shock start model}

An important assumption made by all models considered is that the flash fraction of boiling liquid during the BLEVE contributes to the overpressure of the first peak, either partly (energy models) or fully (expansion controlled model with full liquid simulation). However, this point of view is not shared unanimously. Indeed, both Birk (Birk et al., 2007) and Laboureur (Laboureur et al., 2015) presented overpressure signals with 3 peaks of overpressure as a characteristic pressure signal from a BLEVE. Both assume that the two first peaks originate from the vapor space and hypothesize that the last peak, which is less sharp but potentially longer lasting, could originate from boiling liquid (see Fig. 4b). The experiments conducted in the present study include pressure signals taken closer to the failing tube, allowing a greater distinction to be made between these phenomena. Three peaks are again observed (see Fig. 4a). 

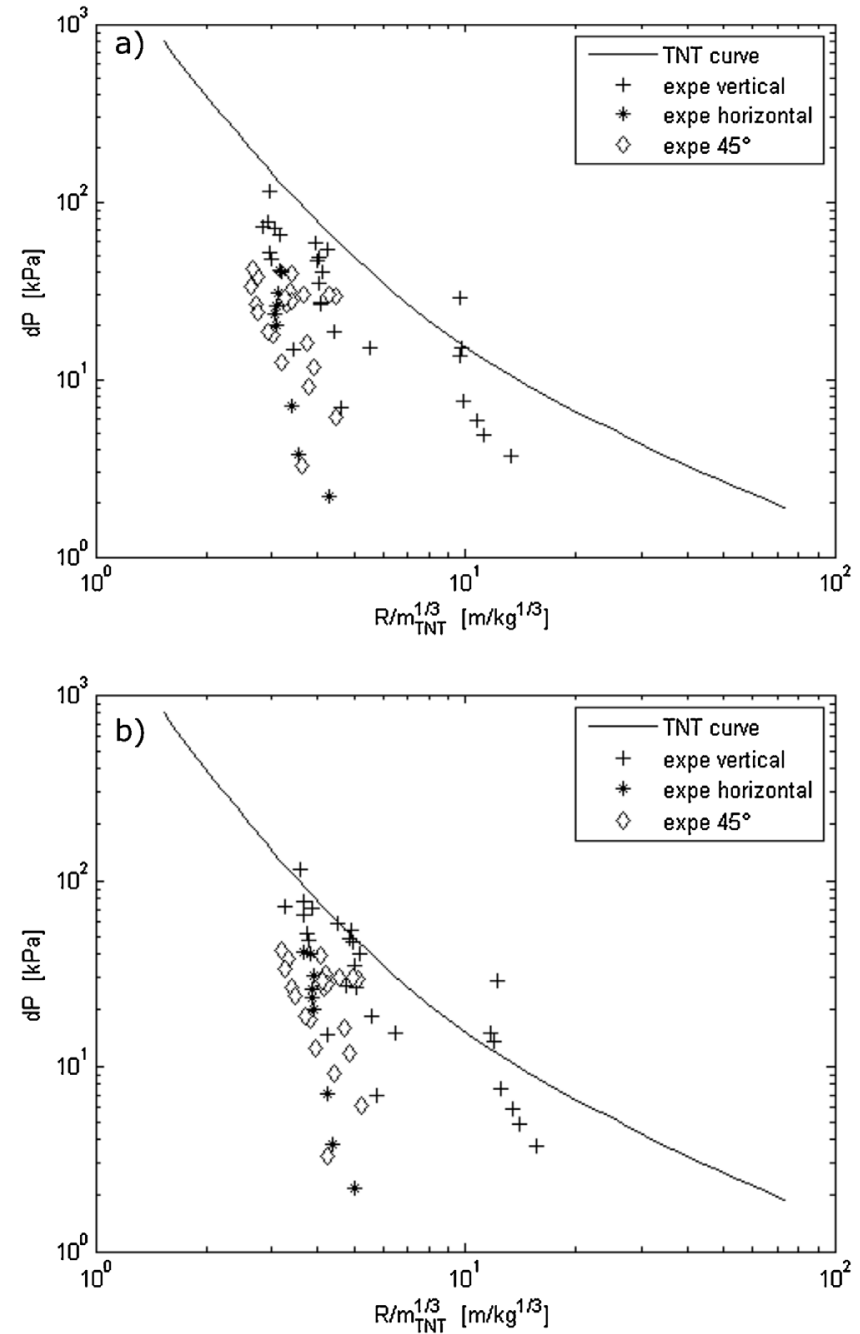

Fig. 8. Comparison of Prugh model (a) and Planas-Cuchi model (b) prediction of experimental results on TNT-curve.

\subsubsection{Theory of shock start}

The prediction of shock overpressure from a gas expansion (Baker, 1985) or hemispherical source of flashing liquid (van den Berg et al., 2004) has been studied previously. However, the models in these studies assume that the shock forms at the interface between the high pressure initial condition and the low pressure atmospheric condition. This phenomenon is validated in the ideal configuration of a sudden release, assuming the interface between high and low pressure chamber disappears instantaneously. But the build-up of this shock must be considered in order to understand the overpressure in the near field with a slower opening process.

Experimental imaging results of a bursting glass sphere containing compressed air clearly illustrate this shock build-up mechanism. In these images a shock appears at a given distance ahead of the sphere fragments, and can be seen to be getting stronger in the successive images. (Glass, 1974). An explanation of this phenomenon is that the compressed air acts as a piston by pushing the atmosphere with successive compression waves that converge to form a shock. The progressive aspect of this shock formation is due to the non-ideal high-pressure chamber rupture. The critical flow through the enlarging opening between glass fragments is like a piston increasing in strength until the opening is large enough for all of the energy to escape. Then, because of the $3 \mathrm{D}$ aspect of the experiment, the shock will expand and decay. The distance at which the shock is fully-formed is the shock start dis-
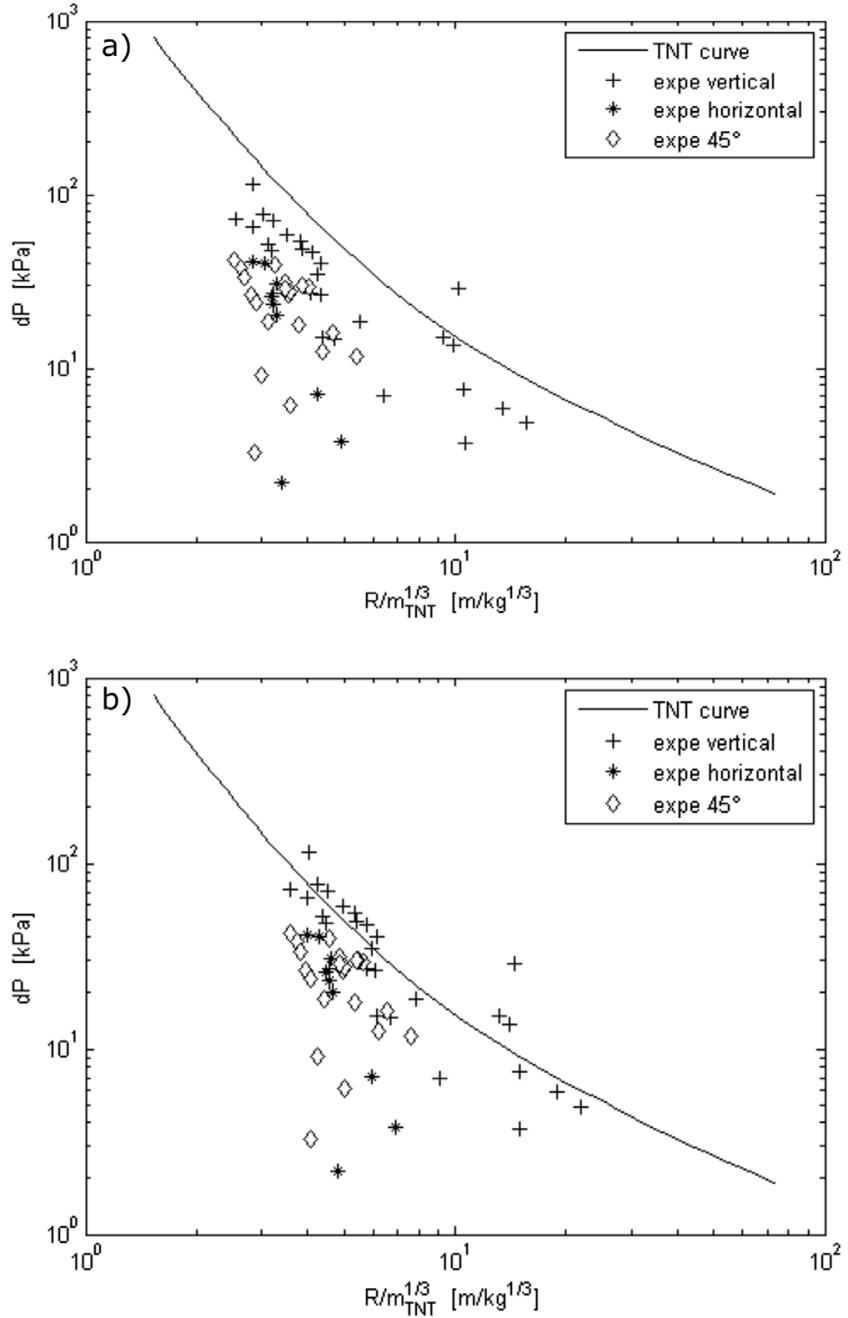

Fig. 9. Comparison of Casal Isentropic (a) and Irreversible (b) prediction of experimental results on TNT-curve.

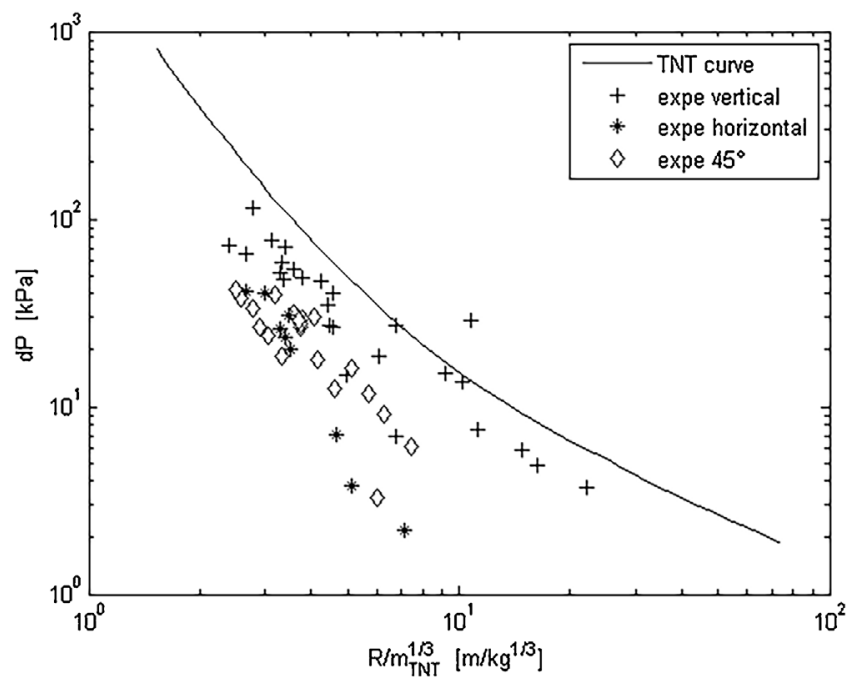

Fig. 10. Comparison of Birk isentropic vapor expansion prediction of experimental results on TNT-curve. 


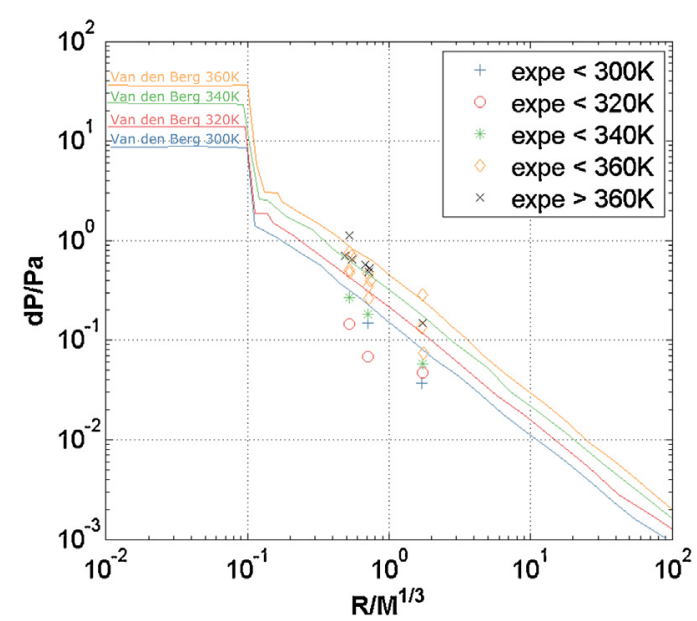

Fig. 11. Comparison of experimental data from vertical gages with Van den Berg simulation results.

tance. This distance is related to the speed of the shock and the time for full opening of the vessel. The shock overpressure will be highest at the shock start position. This overpressure is expected to be related to the overpressure predicted by the shock tube equation (Rothkopf and Low, 1976).

Once the shock reaches the fully-formed state, it will begin decaying with distance. The assumption of far-field decay based on Eq. (1) is made here, considering $n=1.12$ (Laboureur et al., 2015). $d P$ is the overpressure prediction, $d P_{s 0}$ the overpressure at the fullyformed state, $R_{S 0}$ the distance from the tube at which the shock is fully-formed and $R$ is the vertical distance from tube wall upward.

$d P=d P_{s 0} *\left(R_{s 0} / R\right)^{n}$

A correct estimation of the overpressure $d P$, after the shock formation requires knowledge of the shock start position $R_{S 0}$ and the overpressure $d P_{S 0}$.

\subsubsection{Experimental determination of the shock start position}

Shock release details captured by the imaging instruments allow measurement of the parameter $R_{s 0}$ which can be compared with the predictions of the model. Three successive shadowgraph frames of the tube opening illustrate the failure process of the vessel. As explained previously, these images show a growing condensation cloud at the crack opening followed by the progressive formation of a shock wave ahead of the cloud. In these images, shock start is determined to have occurred when the shock is considered to appear strongest (see the example in Fig. 12d), and the measurement for shock start position is taken from that particular image.

The order of magnitude of the $R_{s 0}$ found with this apparatus is between $61 \mathrm{~mm}$ and $88 \mathrm{~mm}$. It corresponds to $1.2 D_{\text {vessel }}$ to $1.8 D_{\text {vessel }}$. These orders of magnitude are smaller than the $R_{S 0}=2.5 D_{\text {vessel }}$ estimated by Laboureur (Laboureur et al., 2015).

Once $R_{s 0}$ is determined, the evaluation of $d P_{s 0}$ and $d P$ is done experimentally from blast data obtained above the tube. $d P_{s 0}$ is evaluated using the decay equation and the closest experimental measurements from the tube $\left(R_{\exp }, d P_{\exp }\right)$ using:

$d P_{s 0}=d P_{\exp } *\left(R_{\exp } / R_{s 0}\right)^{n}$

\subsubsection{Theoretical evaluation of $\mathrm{dP}_{\mathrm{s} 0}$ : shock tube theory and near-field decay}

In order to predict overpressure in tests for which overpressure measurements are not available, the evaluation of overpressure with shock tube equations is computed and evaluated at the surface of the tube based on the initial conditions (TNO, 1997) using:

$P_{\text {fail }} / P_{a}=\left(\overline{P_{S T}}-1\right)\left[1-\frac{\left(\gamma_{\text {fail }}-1\right)\left(a_{\text {exp }} / a_{\text {fail }}\right) \overline{P_{S T}}}{\left[2 \gamma_{\exp }\left\{2 \gamma_{\text {exp }}+\left(\gamma_{\exp }+1\right)\right\} \overline{P_{S T}}\right]^{\frac{1}{2}}}\right]^{-2 \gamma_{\text {fail }} /\left(\gamma_{\text {fail }}-1\right)}$

where $\overline{P_{S T}}=\frac{d P_{S T}}{P_{a}}$. The subscript ST stands for Shock Tube.

From this shock tube initial overpressure, a near-field decay needs to be fitted to match the experimental prediction of $R_{s 0}$, with an $n$ exponent different from that for the far field decay:

$d P_{S T}=d P *\left(R / R_{\text {tube }}\right)^{n}$

Fig. 13 presents the model predictions of several propane tests. For each test, $R_{s 0}$ is evaluated with high speed imaging. The experimental data points "above $28 \mathrm{~cm}$ " (Fig. 13) are the closest measurements obtained in these experiments. Based on Eqs. (1) and (2), $d P_{s 0}$ was calculated thus allowing the scaling of the other experimental measurements to this data. Based on the initial conditions, the shock tube overpressure $d P_{S T}$, at the tube surface is calculated and plotted $\left(R_{T}=2.5 \mathrm{~cm}\right)$.

Finally, to fit the theoretical shock tube overpressure estimation to a function of length scale of the type $\frac{1}{R^{\alpha}}$ with $\alpha$ constant based on experimental far-field behavior, the near-field exponent of the decay must be estimated. This estimation is run for all BLEVE propane tests where $R_{S 0}$ evaluation was possible. Fig. 13 plots experimental data points for all of these cases, with $\mathrm{x}$-axis presenting the distance from vessel to sensor scaled by the value of $R_{S 0}$ corresponding to its test, and the y-axis presenting the overpressure measured by 3 sensors scaled by the value of $d P_{s 0}$ corresponding to its test.

The shock is fully formed at $R / R_{s 0}=1$. The overpressure $d P_{s 0}$ is expected to be the highest overpressure at this location.

Fig. 13 shows the predicted overpressure $d P_{S T}$ from the shock tube equation. As can be seen the $d P_{S T} / d P_{S 0}$ ratio calculated from the shock tube equation is between 1 and 2 for all but two tests. In those two tests $d P_{S T} / d P_{S 0}$ was 3 . This suggests that those two tests saw lower shock overpressures than expected from the shock tube equation. This may be due to the way the tube opened. Fig. 14 shows a trend between the $d P_{S T} / d P_{S 0}$ ratio and the failure pressure. From this trend, the stronger the failure pressure, the faster the tube opens, the closer to 1 the ratio $d P_{S T} / d P_{S 0}$. It is suggested here that the maximum likely overpressure is where the shock forms and it is equal to the overpressure predicted by the shock tube equation $d P_{S T}$. That is $\mathrm{dP}_{\mathrm{SO}}=\mathrm{dP}_{\mathrm{ST}}$ at $\mathrm{R} / \mathrm{R}_{\mathrm{S} 0}=1$.

\section{Limits and openings}

This study has focused mainly on the maximum peak overpressure. However, as mentioned in the discussion of Fig. 4, other parameters need attention in order to understand the full physics of the near field BLEVE. The hypothesis of a second overpressure peak from the vapor space requires validation. The impact of explosive liquid boiling may not be so strong on the maximum overpressure, but it adds a significant amount of energy to other hazards, such as blast wind, projection of vessel fragments, and load impact on the ground.

A source of error in this study is the accuracy of the determination of $R_{s 0}$. The retroreflective shadowgraph gives interesting large field views of the shock propagation but is limited when it comes to examining the shock formation near the vessel opening. Principally, the shock start is not a sudden phenomenon. There is subjectivity in choosing the appropriate criterion for visually detecting a clear shock. This uncertainty can range from 1 to 2 frames. With $50 \mu \mathrm{s}$ between each frame, this induces an error of $20 \mathrm{~mm}$ for $R_{S 0}$ : $d R_{s 0}=0.4 D_{\text {vessel }}$. 

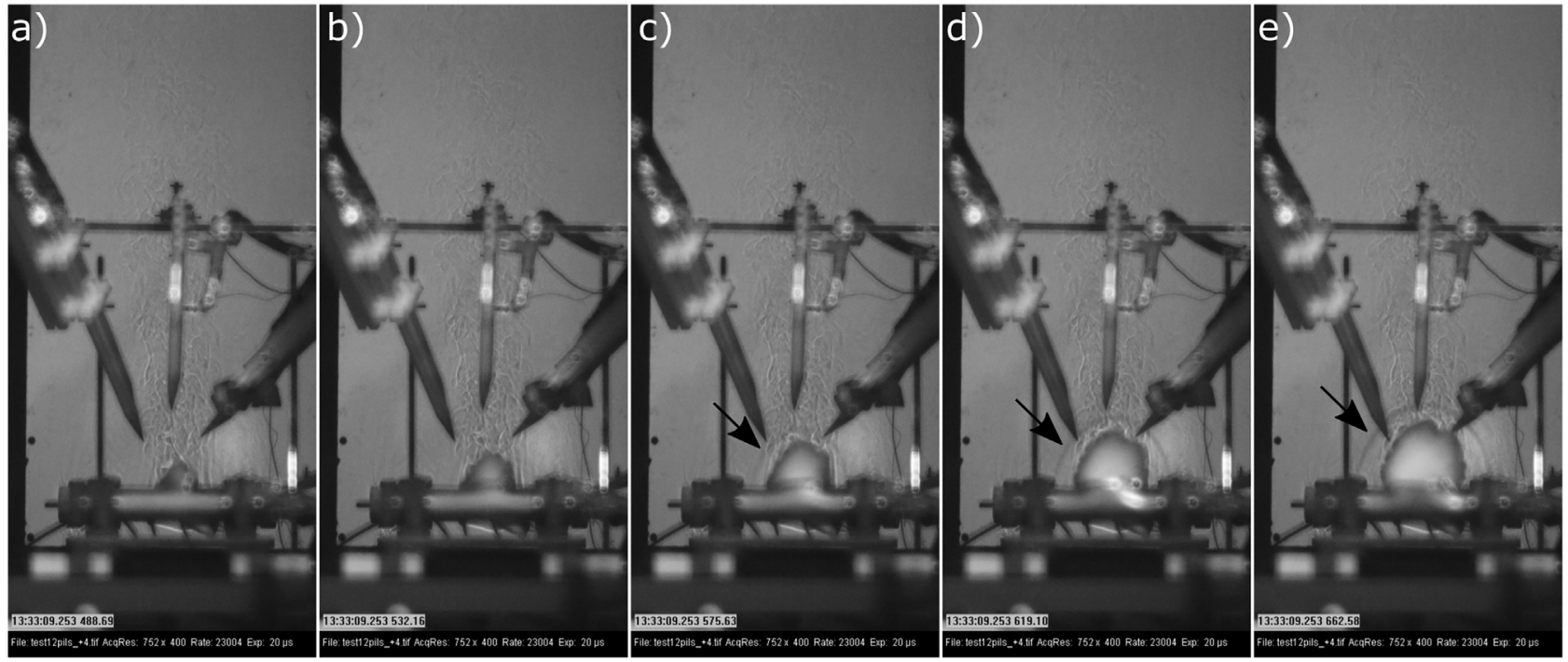

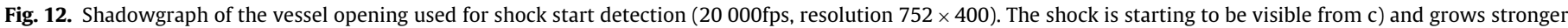
on d) and e).

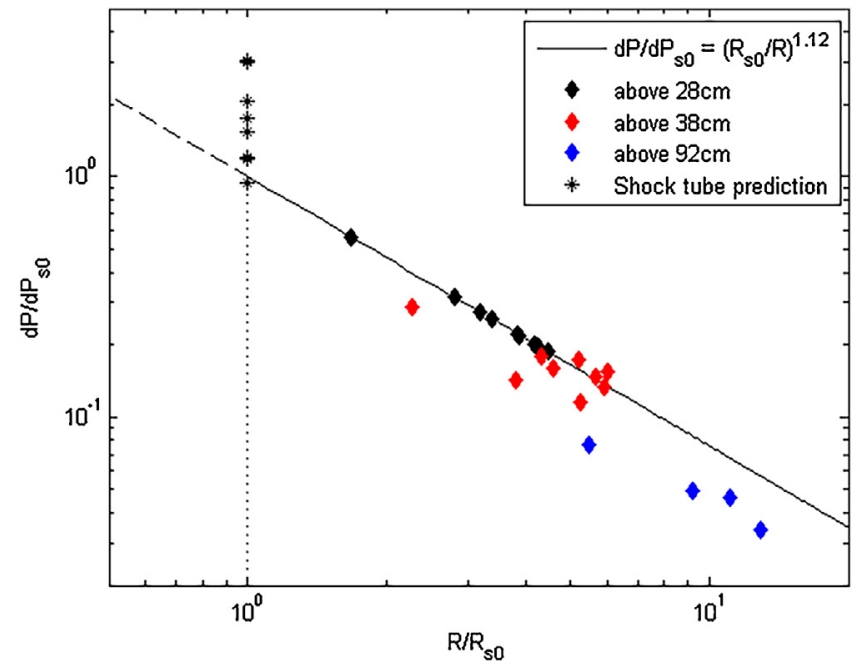

Fig. 13. Overpressure results from top gages scaled according to the shock build-up modelling.

To reduce this error and improve the accuracy of the shock start evaluation, one need to improve the following steps from most to least significant:

- Set an objective criterion on the shadowgraph will remove the subjective error. Such a criterion can be maximum grey level of the shock or its thickness on the images.

- Get rid of the fire bellow the tube and find another source of heating. Fire generates strong heat convection in the air above the tube visible through shadowgraph, which makes the shock detection less distinctive.

- Increase the spatial resolution of the imaging near the shock generation allows seeing the shock clearer. This is possible if the shadowgraph is made on a smaller area around the tube opening.

- Increase the video acquisition speed, with faster camera, but also stronger lighting and proper adjustment of the relevant field of view captured.

The shock start approach is based on existing theories of the shock tube, relating the pressure ratios to the shock strength. Using

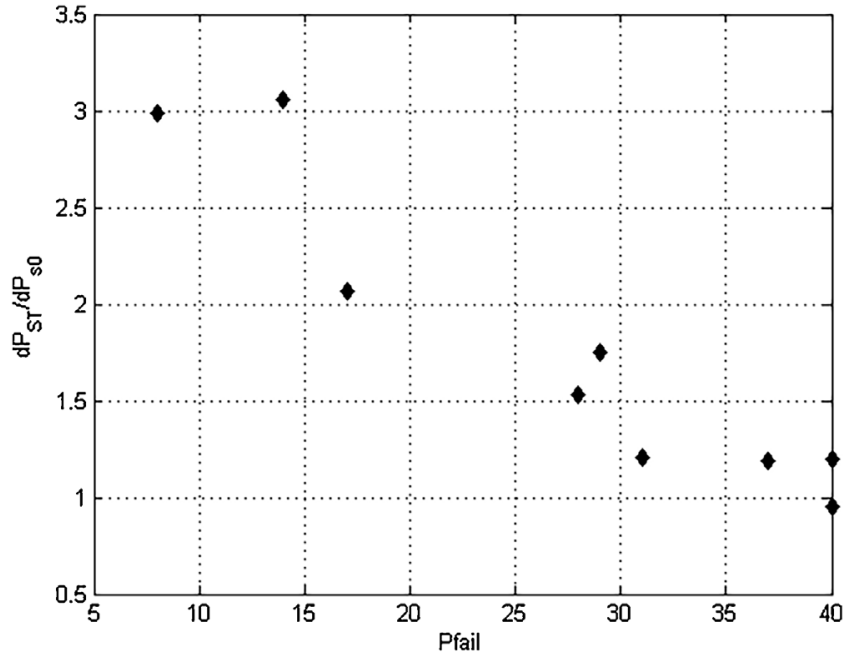

Fig. 14. $d_{\mathrm{ST}} / \mathrm{dP}_{\mathrm{s} 0}$ ratio behavior with failure pressure.

this theory for BLEVE near-field overpressure is interesting as this model has been proven to work for many applications. It is applied to different phases of decay of the shock. However, the physics of the shock build-up taking place over a long-time span and longer length may not be modeled well with the shock tube theory, and a finer description of the build-up followed by the decay may be required.

Finally, the present tests were performed with small scale vessels. Derived ratios of $R_{s 0}$ over the tube diameter were obtained and agreed well with other small scale experiments (Laboureur et al., 2015). However, the application of these results to full scale storage and transport vessels is not clear. Since the shock build-up depends on the time to full opening of the vessel, a larger vessel will have a longer opening time. The propagation of the crack along the length of the vessel depends on the length of the vessel. An extra factor that includes the vessel length needs to be considered in order to scale $R_{s 0} / D$ up to a life-size vessel.

\section{Conclusion}

This study introduces a new set of experimental data to help understand the overpressure hazard of a BLEVE in the near-field. 
The coupling of overpressure measurement and optical shock detection through the use of high speed retroreflective shadowgraphy supplements existing experimental data on BLEVEs as data on the overpressures measured from above the vessel is currently lacking. While there is fairly good agreement with the thermodynamic prediction models currently available in the literature, the results provide some evidence that vapor expansion is the sole contributor to the first shock and maximum peak overpressure. Moreover, unlike the ideal conservative case of instant opening of a vessel (or diaphragm in the case of shock tube), a vessel opens over a finite span of time. This leads to the phenomenon of progressive shock build-up near a vessel, leading to a new approach in estimating the near-field overpressure of a BLEVE.

A model based on this phenomenon is presented and attempts to predict the near-field overpressure with an approach based on compressible flow theories without the use of the heavy computational power of CFD in order to give a quick estimation of the shock strength. It uses two physical parameters: the shock start distance from the opening, measured experimentally or estimated from experience; and the shock overpressure equivalent from shock tube theory. These parameters are used as indicators of the explosion strength, replacing the calculation of the expansion energy used in thermodynamic models in the literature.

A better understanding of the dynamic of shock start is needed for future testing in order to predict the starting distance and for cases where imaging is not available. Some parameters such as the size and velocity of the opening of the vessel, as well as the liquid fill level before rupture, and the failure pressure will help in understanding the formation of the shock.

\section{Acknowledgment}

This work was supported by the Natural Sciences and Engineering Research Council of Canada.

\section{References}

Abbasi, T., Abbasi, S.A., 2007. The boiling liquid expanding vapour explosion(BLEVE): mechanism, consequence assessment, management. J. Hazard. Mater. 141, 489-519, http://dx.doi.org/10.1016/j.jhazmat.2006.09.056.

Baker, W.E., Kulesz, J.J., Ricker, R.E., Bessey, R.L., Westine, P.S., Parr, V.B., Oldham, G.A., 1977. Workbook for Predicting Pressure Wave and Fragment Effects of Exploding Propellant Tanks and Gas Storage Vessels.

Baker, W.E., 1985. Explosion Hazards and Evaluation. Elsevier Scientific Pub. Co., http://dx.doi.org/10.1016/0010-2180(85)90099-9.
Birk, A.M., Davison, C., Cunningham, M., 2007. Blast overpressures from medium scale BLEVE tests. J. Loss Prev. Process Ind. 20, 194-206, http://dx.doi.org/10. 1016/j.jlp.2007.03.001.

Birk, A.M., Heymes, F., Aprin, L., Slangen, P., Eyssette, R., Lauret, P., 2016. Near field blast effects from BLEVE. Chem. Eng. Trans. 48, 283-288, http://dx.doi.org/10. 3303/CET1648048.

CCPS - American Institute of Chemical Engineers, 1994. Guidelines for Evaluating the Characteristics of Vapor Cloud Explosions, Flash Fires and BLEVEs. Wiley-AIChE.

Casal, J., Salla, J.M., 2006. Using liquid superheating energy for a quick estimation of overpressure in BLEVEs and similar explosions. J. Hazard. Mater. 137 1321-1327.

Genova, B., Silvestrini, M., Leon-Trujillo, F.J., 2008. Evaluation of the blast-wave overpressure and fragments initial velocity for a \{BLEVE\} event via empirical correlations derived by a simplified model of released energy. J. Loss Prev. Process Ind. 21, 110-117.

Glass, I.I., 1974. Shock Waves and Man. University of Toronto Press Toronto.

Hargather, M.J.M.J., Settles, G.S.G.S., 2009. Retroreflective shadowgraph technique for large-scale flow visualization. Appl. Opt. 48, 4449-4457, http://dx.doi.org/ 10.1364/AO.48.004449.

Hemmatian, B., 2016. Contribution to the Study of Boiling Liquid Expanding Vapor Explosions and Their Mechanical Effects. Universitat Politecnica de Catalunya.

Heymes, F., Aprin, L., Birk, A.M., Slangen, P., Jarry, J.B., François, H., Dusserre, G., 2013. An experimental study of an LPG tank at low filling level heated by a remote wall fire. J. Loss Prev. Process Ind. 26, 1484-1491, http://dx.doi.org/10.1016/j. jlp.2013.09.015.

Laboureur, D., Heymes, F., Lapebie, E., Buchlin, J.M., Rambaud, P., 2014. BLEVE overpressure: multiscale comparison of blast wave modeling. Process Saf. Prog. 33 274-284, http://dx.doi.org/10.1002/prs.11626.

Laboureur, D., Birk, A.M., Buchlin, J.M., Rambaud, P., Aprin, L., Heymes, F., Osmont A., 2015. A closer look at BLEVE overpressure. Process Saf. Environ. Prot. 95, 159-171, http://dx.doi.org/10.1016/j.psep.2015.03.004.

Laboureur, D., 2012. Experimental Characterization and Modeling of Hazards: BLEVE and Boilover (PhD Dissertation). Von Karman Institute for Fluid Dynamics; Universite Libre de Bruxelles.

Planas-Cuchi, E., Salla, J.M., Casal, J., 2004. Calculating overpressure from BLEVE explosions. J. Loss Prev. Process Ind. 17, 431-436, http://dx.doi.org/10.1016/j. jlp.2004.08.002.

Prugh, R.W., 1991. Quantitative evaluation of bleve hazards. J. Fire Prot. Eng. 3, 9-24, http://dx.doi.org/10.1177/104239159100300102.

Rothkopf, E.M., Low, W., 1976. Shock formation distance in a pressure driven shock tube. Phys. Fluids 19, 1885, http://dx.doi.org/10.1063/1.861423.

TNO, 1997. CPR 14E (Yellow Book) Methods for the Calculation of Physical Effects Due to Releases of Hazardous Materials (liquids and Gases).

van den Berg, A.C., van der Voort, M.M., Weerheijm, J., Versloot, N.H.A., 2004. Expansion-controlled evaporation: a safe approach to BLEVE blast. J. Loss Prev. Process Ind. 17, 397-405.

Van den Berg, A.C., Lannoy, A., 1993. Methods for vapour cloud explosion blast modelling. J. Hazard. Mater. 34, 151-171, http://dx.doi.org/10.1016/03043894(93)85003-W.

Van den Berg, A.C.C., 2008. Blast charts for explosive evaporation of superheated liquids. Am. Inst. Chem. Eng. Process Saf. Prog. 27, 219-224, http://dx.doi.org/ 10.1002 /prs.

Yakush, S.E., 2016. Model for blast waves of boiling liquid expanding vapor explosions. Int. J. Heat Mass Transf. 103, 173-185, http://dx.doi.org/10.1016/ j.ijheatmasstransfer.2016.07.048. 